\title{
Analysis of Speeding Behaviour During Approaching the U-Turn Facility Road Segment Based On Driving Simulation Test
}

\author{
M. S. Nemmang ${ }^{1}, R . \operatorname{Rahman}^{1,{ }^{*}}, M . M$. Rohani $^{1}, N$. Mashros $^{2}$, and $J . M d \operatorname{Diah}^{3}$ \\ ${ }^{1}$ Department of Infrastructure and Geomatic, University Tun Hussein Onn Malaysia, Batu Pahat \\ ${ }^{2}$ Faculty of Civil Engineering, Universiti Teknologi Malaysia (UTM), Johor Bahru, Johor, Malaysia \\ ${ }^{3}$ Faculty of Civil Engineering, Universiti Teknologi Mara, Shah Alam, Selangor 40450, Malaysia
}

\begin{abstract}
The main purose of this study is to analysis the speeding behavior during approaching the U-turn facility road segment based on driving simulation test. In previous studies, it has been shown that speeding behavior is a complex problem that requires a full understanding of drivers' attitudes and beliefs. Such understanding is needed to improve the speeding behavior of drivers that comes from the effective design and interventions. Therefore, this study will analyse the speeding behavior in approaching the U-turn facility as a key variable in this study which may affect the collision result. Totally 50 participants were recruited in this experiments based on driving simulator. The scenarios and road environment in the driving simulator were based on site location at FT050 Jalan Batu Pahat - Kluang, Johor. Results shows significant increase in speed of up to $40.01 \%$ more than the speed limit at the approaching the Uturn facility road segment. The paper concluded that speeding behavior during approaching the U-turn facility road segment based on driving simulation test will trigger significant increasing of speed.
\end{abstract}

\section{Introduction}

This study is conducted to find out the driver speeding behavior in the area of U-turn at FT050 form Batu Pahat to Kluang. FT050 has six (6) midblock U-turn facility in total from Batu Pahat to Parit Raja with only two (2) U-turn facility available for heavy vehicles. The speed profile is an important tool for road safety especially in the evaluations and in design process of existing toad because it can be used for safety considerations. The data recorded by Royal Malaysia Police in 2012 [1] showed that accident rate were increasing every year where in year 2012 the number of accident was 62,316 with 1,073 fatal and location for this study which is in Batu Pahat, where it is the second highest in Johor the number of accident recorded was 7,439 with 176 fatal recorded which is the highest in Johor during that year. Sadly, in 2015 it keeps increasing with the 197 fatal. Abdul Manan [2] and Abdul Manan \& Várhelyi [3] also mentioned that Batu Pahat - Kluang FT050 road recorded 1000 accidents and 36 deaths since 2006. This study was using the driving simulator to collect the data.

\footnotetext{
*Corresponding author: raha@uthm.edu.my
} 
However, when drivers driving in actual driving situations rear-end risk still exists. The development of driving simulator with character safer driving environment, easier to use, and lower cost makes the experiment for data collection in a more convenient way. Studies using driving simulator have been conducted in many fields such as using driving simulator in model development and to examine the effect of intersection and as stated by Md Diah et al. [4] and Nemmang and Rahman [5].

Speed choice is one of the most studied driver behaviors. One reason may be because speed is strongly related to accident risk. Therefore, the studies on speeding behavior are important in this road especially in approaching the U-turn facility because the speed limit in the U-turn area are $60 \mathrm{~km} / \mathrm{h}$ where is at the roadway before and approaching U-turn segment was $90 \mathrm{~km} / \mathrm{hr}$ the reduction and increasing speed can lead the accident as studied by Rahman and Ben-Edigbe [6]. Studies of speeding behavior have been conducted in many aspects. Mehmood, [7] studies the speeding behavior used radar gun to measure the spot speed of randomly selected vehicles from three major arterial roads in order to assess the current extent of the speeding problem in $\mathrm{Al}$ Ain. The results indicated that speeding behavior contributing to $37 \%$ of severe road crashes. While Montella et al. [8] studies speeding behavior in rural intersections using driving simulator and the results showed that that intersections significantly affect drivers' speed behavior.

Some researchers also study about the travel speed at the multilane. Rahman and BenEdigbe [6] trigger significant travel speed reduction in median openings zone facilities irrespective of their traffic conflicts minimization merits. While Daniel et al. [9] studies about the speed patterns on traffic calmed. They provided that driver choice of speed not only when traversing the devices but also as they move towards and away from the devices that affected into the effects of traffic calming devices on driver behavior. Mashros et al. [10] explore about the mean speed at the dry and rainfall condition. The research successfully finds out the speed reduction in dry and rainfall condition. Moreover, Rohani et al. [11] assess the impact of business and non-business hours on speed and acceleration of car drivers. The researcher divided the road into four (4) segment and find out the speed in every segment during the business hour and non-business hour. Speed study have been familiar for the researchers in order to reduce the number of accident and find out the driver behavior in choosing the speed. Usually, mean speed will be used to find out the average speed of driver tend to drive in certain area such as in U-turn area. Mean speed is calculated as the sum of all speeds divided by the number of speed observations and a measure of the central tendency of the data. This speed is believed as an indicator of average travel speed. Therefore, this studies find out the speed behavior of drivers in order to minimize the probability of accident especially in U-turn area.

\section{Methodology}

In this paper, the methodology in collecting the data is divided into 3 steps.

\section{Step 1: Participant}

The process begins with a recruited a total of 20 participants to use the driving simulator as a sample. During the selection of the participants, gender (10 males vs 10 females). The participants were given time to practice the driving simulator to make sure they are familiar with the road and condition. The most important thing this group of people should have a valid Malaysian driving license and must in 19 years old and above. In order to ensure the availability of the data, participants were excluded for sickness and for the sleep debt which may influence a normal driving. 


\section{Step 2: Apparatus}

The apparatus in this experiment was conducted by a fixed- basis driving simulator in University Teknologi Mara (UITM) by using Automotive Simulator for Driver's Behavior and Competency Evaluation (ASIS). The driving simulator (Fig. 1) give the participant drive like driving a real car on a real road because it can simulate driving scenarios and various kinds of road traffic environments. The vehicle cockpit is based on the true steering simulation system, accelerated and brake pedal system, real instrument control interface, vibration and noise simulation system and the vehicle is located in a 180 degree rearview that can display virtual road environment.

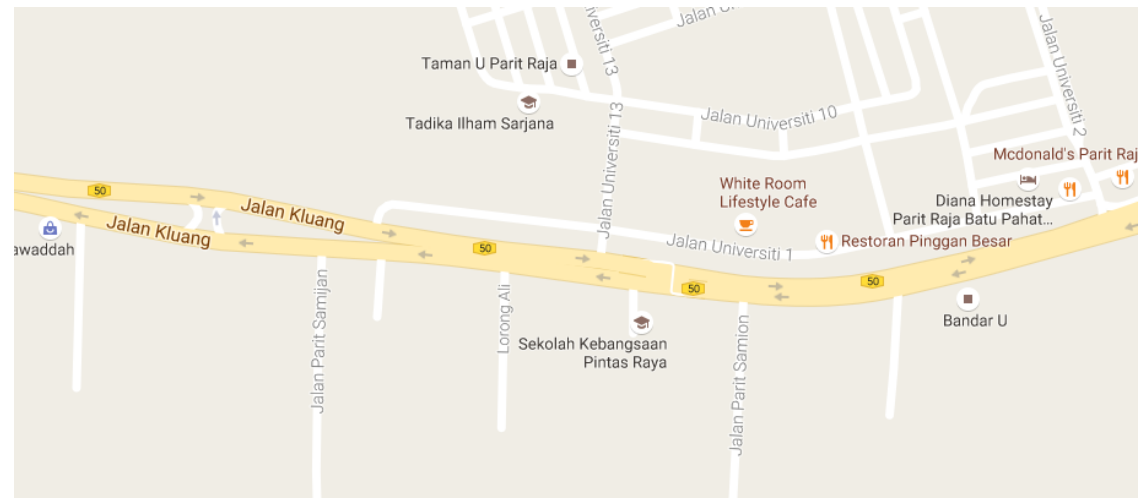

Fig. 1. Area of research study at FT050

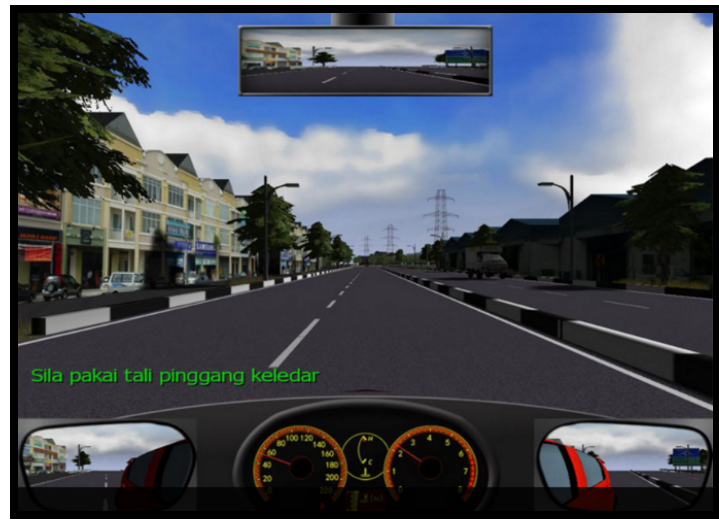

Fig. 2. Driving simulator screen simulation

\section{Step 3: Scenarios}

The purpose of this study is to study the drivers speeding behavior in approaching the Uturn facility. Thus the scenarios or road environment are based on the road environment of FT050 as shown in Fig. 2. To meet the requirements of designing scenarios and simulating virtual traffic environment, a set of software as shown in Fig. 3 are adopted. Other than that, the roads design was dual carriageway highway with a median that give participants choose the best lane and speed for their driving. The road and the U-turn area development has a midblock in the middle of the road. The road providing the U-turn signboard which is $150 \mathrm{~m}$ before the U-turn area and at the U-turn itself that given the driver warning and guide 
that U-turn area at the front. The length of the road was $700 \mathrm{~m}$ which is $500 \mathrm{~m}$ before the Uturn area and $200 \mathrm{~m}$ after the U-turn. It gives the driver a chance to get momentum on the speed of the vehicle in approaching the U-turn area. Therefore, driver will be driving with their own intentions without any disruptions from the road design.

\section{Results and findings}

\subsection{Analysis of drivers speeding behavior}

In this paper, the analysis of driver behavior focuses on the speeding behavior of the driver in the U-turn area. Table 1 presents the mean speed of driver driving from the driving simulation based on the road environment of FT050 from Batu Pahat to Kluang at the Uturn area of KM15. The speed limit in the area of U-turn area which is $150 \mathrm{~m}$ from the Uturn is $60 \mathrm{~km} / \mathrm{h}$. From the Fig. 3, the histogram shows that the driver behavior tends to speeding in the U-turn area where the graph nearly uniforms from all the drivers. The highest average speed is $91.95 \mathrm{~km} / \mathrm{h}$ which is $31.95 \mathrm{~km} / \mathrm{h}$ more than the speed limit. The lowest average speed comes from the driver 19 with speed $62.87 \mathrm{~km} / \mathrm{h}$.

Table 1. Mean speed of driver

\begin{tabular}{|c|c|c|c|}
\hline Drivers & Mean Speed $(\mathbf{k m} / \mathbf{h})$ & Drivers & Mean Speed $\mathbf{( k m} / \mathbf{h})$ \\
\hline Driver 1 & 86.88 & Driver 11 & 78.15 \\
\hline Driver 2 & 88.17 & Driver 12 & 85.93 \\
\hline Driver 3 & 85.29 & Driver 13 & 90.41 \\
\hline Driver 4 & 91.95 & Driver 14 & 87.22 \\
\hline Driver 5 & 90.60 & Driver 15 & 87.26 \\
\hline Driver 6 & 83.16 & Driver 16 & 91.52 \\
\hline Driver 7 & 86.55 & Driver 17 & 62.91 \\
\hline Driver 8 & 88.06 & Driver 18 & 83.99 \\
\hline Driver 9 & 87.72 & Driver 19 & 62.87 \\
\hline Driver 10 & 87.72 & Driver 20 & 74.83 \\
\hline
\end{tabular}

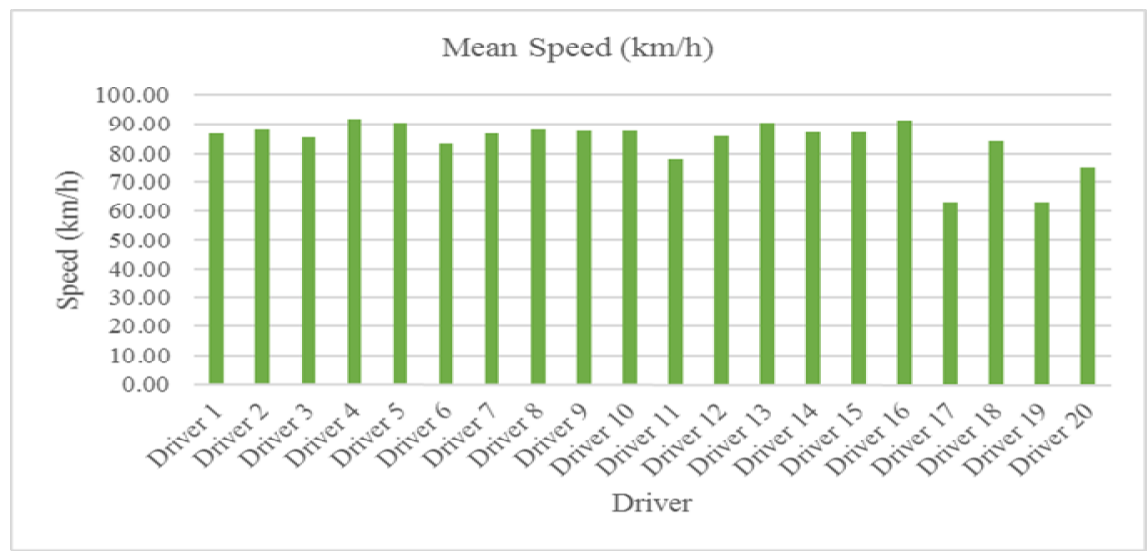

Fig. 3. Mean speed histogram 
Graphical view of the speeding behavior of the driver shown in Fig. 4. It shows that the speeding behavior in the area of U-turn nearly closed between all the drivers as shown in the graph line for speed differences that formed nearly flat line from driver 1 to driver 16 . Only driver 16 and 19 have speed nearly $60 \mathrm{~km} / \mathrm{h}$ that follows the speed limit of the area. It shows that drivers tend to speeding in this area where it can bring into an accident.

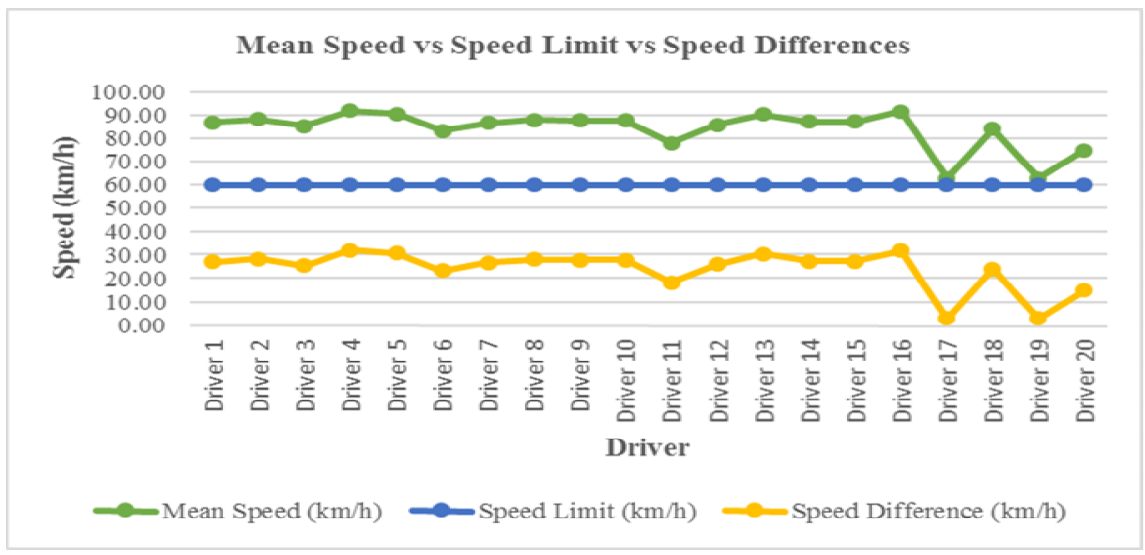

Fig. 4. Graphical view of mean speed vs speed limit vs speed differences

The summary of average speeds is presented in Table 2. Result shown that average speeds in the U-turn area increasing in $40.01 \%$ which is the average speed is $84.06 \mathrm{~km} / \mathrm{h}$. Ttest was performed on these speed data and the result is given in Table 3. Result indicated that the speed increasing in average speed was found to be statistically significant.

Table 2. Descriptive analysis of speeding

\begin{tabular}{|l|r|r|r|r|}
\hline & $N$ & Mean & Std. Deviation & $\begin{array}{c}\text { Std. Error } \\
\text { Mean }\end{array}$ \\
\hline Mean_Speed & 20 & 84.0595 & 8.32670 & 1.86191 \\
Speed_Differences & 20 & 24.0595 & 8.32670 & 1.86191 \\
\hline
\end{tabular}

Table 3. T-test for speeding behavior

\begin{tabular}{|c|c|c|c|c|c|c|}
\hline & \multicolumn{6}{|c|}{ Test Value $=0$} \\
\hline & \multirow[b]{2}{*}{$t$} & \multirow[b]{2}{*}{ df } & \multirow[b]{2}{*}{ Sig. (2-tailed) } & \multirow{2}{*}{$\begin{array}{l}\text { Mean } \\
\text { Difference }\end{array}$} & \multicolumn{2}{|c|}{$\begin{array}{c}\text { 95\% Confidence Interval of the } \\
\text { Difference }\end{array}$} \\
\hline & & & & & Lower & Upper \\
\hline Mean_Speed & 45.147 & 19 & .000 & 84.05950 & 80.1625 & 87.9565 \\
\hline Speed_Differences & 12.922 & 19 & .000 & 24.05950 & 20.1625 & 27.9565 \\
\hline
\end{tabular}

\subsection{Speeding behavior based on gender}

Descriptive statistics on gender was shown in Table 4. It was found that male drivers seemed to have a higher speed than the female drivers. It shows that mean speed for male drivers is $89 \mathrm{~km} / \mathrm{h}$ while female drivers has a mean speed $79 \mathrm{~km} / \mathrm{h}$ which is about $10 \mathrm{~km} / \mathrm{h}$ lower than male drivers. The significance T-test as shown in Table 5 shows that speeding 
behavior between male and female drivers has a significant differences where the $\mathrm{P}$ value is 0.005 which is lower than 0.05 .

Table 4. The descriptive statistics of speeding behavior by gender

\begin{tabular}{|l|r|r|r|}
\hline Gender & \multicolumn{1}{|c|}{ N } & \multicolumn{1}{|c|}{ Mean } & Std. Deviation \\
\hline Male & 10 & 88.9340 & 1.95528 \\
Female & 10 & 79.1850 & 9.47347 \\
Total & 20 & 84.0595 & 8.32670 \\
\hline
\end{tabular}

Table 5. The significance T-test of speeding behavior by gender

\begin{tabular}{|ll|r|r|r|r|r|}
\hline & \multicolumn{1}{|c|}{$\begin{array}{c}\text { Sum of } \\
\text { Squares }\end{array}$} & \multicolumn{1}{c|}{ df } & Mean Square & \multicolumn{1}{c|}{$F$} & \multicolumn{1}{c|}{ Sig. } \\
\hline Mean_Speed * Gender & Between Groups (Combined) & 475.215 & 1 & 475.215 & 10.157 & .005 \\
\cline { 2 - 8 } & Within Groups & 842.128 & 18 & 46.785 & & \\
\cline { 2 - 8 } & Total & 1317.343 & 19 & & & \\
\hline
\end{tabular}

\section{Conclusion}

Research findings suggested that in general, speeding behavior of the driver in the area of the U-turn not affected by the signboard and the speed limit. Even though all the drivers have been given warning by all the signboard, drivers were ignored all the signboard where the research found that drivers were drive up to $40.01 \%$ significantly faster than the speed limit. It shows that, drivers tend to speeding without notices the signboard and speed limit that may cause to an accident with the U-turn vehicles. Other than that, speeding behavior based on gender shows that male drivers tend to speeding where it is higher than a female driver when approaching the U-turn facility road segment.

This research is supported by the GPPS of Universiti Tun Hussein Onn Malaysia (UTHM) in Vot U439.

\section{References}

[1] Polis Diraja Malaysia, Laporan Perangkaan Kemalangan Jalan Raya Malaysia, Malaysia, (2012)

[2] M.N. Abdul Manan, Motorcycle Crashes in Malaysia - Status, Risk Factors and Interventions, MIROS, (2015b)

[3] M.N. Abdul Manan, and A. Várhelyi, Motorcycle fatalities in Malaysia. IATSS Research, 36(1), 30-39, (2012)

[4] J. Md Diah, M.Y. Abdul Rahman, M.A. Adnan, I. Atan, Weaving section flow model at the weaving area of Malaysian conventional roundabout, Journal of Transportation Engineering, 136(8), 782-792 (2010)

[5] M.S. Nemmang, R. Rahman, An Overview of vehicles lane changing model development in approaching at u-turn facility road segment, Jurnal Teknologi, 7, 59-66 (2016)

[6] R. Rahman, J. Ben-edigbe, Impact of multilane median openings zone on travel speed,Technology Journal, 4, 15-20 (2015)

[7] A. Mehmood, Determinants of speeding behavior of drivers in Al Ain (United Arab Emirates), Journal of Transportation Engineering, 135, 721-729 (2009) 
[8] A. Montella, V. Claudio, F. Mauriello, drivers' speed behaviour at rural intersections: Simulator experiment and real world monitoring, Road Safety and Simulation, 1-14 (2011)

[9] B.D. Daniel, N. Alan, G. Koorey, Investigating speed patterns and estimating speed on traffic-calmed streets, Proc. of the IPENZ Transportation Group Conference, Auckland, (2011)

[10]N. Mashros, R. Rahman, J. Ben-Edigbe, Exploration of sample quantiles and mean speed distributions, International Conference on Statistics in Science, Business and Engineering: Empowering Decision Making with Statistical Sciences, ICSSBE 2012 Proceedings, 158-161, (2012)

[11]M. Rohani, B.D. Daniel, M.Y. Aman, J. Prasetijo, A.A. Mustafa, R. Rahman, Business hours vs non - business hours in business zone: Impact on speed and acceleration, Jurnal Teknologi, 4, 71-77 (2016) 